\title{
FATORES DETERMINANTES NA MUDANÇA DO PADRÃO DE PRODUÇÃO E CONSUMO DA MANGA NO MERCADO NACIONAL
}

\author{
Diogo de Oliveira Araújo* \\ João Artur Alves Moraes** \\ José Luiz Moreira de Carvalho****
}

RESUMO: A cultura da manga no Brasil passou por um processo de expansão com a utilização de técnicas como a aplicação de reguladores de crescimento, o estresse hídrico e o manejo da floração. Outro fator relevante envolveu a mudança nas variedades produzidas. Entretanto, a escolha das variedades a serem produzidas pode receber diversas influências, tanto relacionados a fatores ligados à produção, quanto da fisiologia das próprias frutas ou do mercado consumidor. Nesse sentido, o objetivo deste trabalho consistiu em identificar os fatores que provocaram essas mudanças nos padrões de produção e consumo da manga no Brasil, especificamente na questão das variedades da fruta, e também identificar as tendências futuras para esse mercado. A metodologia escolhida para isso foi a do painel de especialistas. Foi constatado que as mudanças no cultivo da manga em proporções comerciais tiveram como fator motivador a possibilidade da exportação da fruta. Baseados nisto, os produtores se adaptaram às exigências que eram ditadas pelo mercado internacional, optando por variedades como a Tommy Atkins, que possuíam características essenciais para a exportação, como resistência ao manuseio e transporte. As perspectivas futuras indicam uma estabilização das variedades, com ressalvas à variedade Palmer, que apresenta aumento significativo de sua oferta. As variedades Espada e Rosa continuarão sendo demandadas, porém, restritas a fatores culturais e nichos de mercado.

PALAVRAS-CHAVE: Fruticultura; Padrões de Consumo.

Graduando em Engenharia de Produção pela Universidade Federal do Vale do São Francisco (UNIVASF), Brasil.

** Graduando em Engenharia de Produção pela Universidade Federal do Vale do São Francisco (UNIVASF), Brasil.

*** Docente Associado I do curso de Engenharia de Produção da Universidade Federal do Vale do São Francisco (UNIVASF), Brasil. E-mail: jose.carvalho@univasf.edu.br 


\title{
DETERMINING FACTORS IN CHANGES OF MANGO PRODUCTION AND CONSUMPTION PATTERNS ON THE BRAZILIAN MARKET
}

\begin{abstract}
Mango culture in Brazil has gone through an expansion process when growth regulators, hydric stress and florescence management were employed. Another relevant factor involved changes in the produced varieties. However, the choice of mango varieties may be affected by production-linked factors, the fruit 's physiology and consumers. Current paper identifies the factors that caused changes in mango production and consumption patterns in Brazil, specifically with regard to fruit variety, coupled to the market's future trends. A board of experts was employed as a methodology. Commercially-based changes in mango culture were motivated by the possibility of exporting the fruit. The producers adapted themselves to the requirements of the international market and opted for such varieties as the Tommy Atkins variety, with specific export characteristics, such as tolerance in handling and transport. Future trends indicate the stabilization of varieties, except the mango Palmer with high supply increase. Varieties Espada and Rosa are still demanded but they are restricted by cultural features and market niches.
\end{abstract}

KEY WORDS: Fruit culture; Consumption patterns.

\section{INTRODUÇÃO}

A fruticultura é um dos setores de maior destaque do agronegócio brasileiro, com uma grande variedade de culturas, produzidas em todo o país e em diversos climas. O Brasil é o terceiro maior produtor de frutas no mundo, ficando atrás apenas de China e Índia, o que mostra a relevância do setor para a economia brasileira (SEBRAE, 2015).

Segundo Fávero (2008), entre as culturas responsáveis pelo alto volume de produção e exportação, pode se destacar a manga. Esta frutífera está presente em todas das regiões brasileiras, mas é nas regiões Nordeste e Sudeste que o cultivo da mesma é intensificado com propósito de atender necessidades do mercado interno e externo. $\mathrm{O}$ mesmo autor relata que as produções iniciais da fruta atendiam somente ao mercado interno, através de variedades como: Espada, Rosinha, Itamaracá, etc. A partir de 1980, com o início das exportações da fruta, observou-se que os padrões de consumo se direcionaram para a variedade Tommy Atkins. 
Silva e Coelho (2010) dizem que o processo de ampliação da cultura da manga no Brasil ocorreu, principalmente, a partir de meados dos anos 1980 e perdurou por toda a década de 1990, sendo que esse crescimento ocorreu, em especial, nas regiões Nordeste e Sudeste. Os mesmos autores ainda ressaltam que no período de 1990 a 2007 houve um crescimento da área cultivada da manga na ordem de $67,56 \%$, tal fato foi concebido principalmente por causa das regiões Nordeste e Sudeste, que mantiveram seu crescimento na produção da manga.

Diante dos diferentes mercados consumidores da manga e de suas respectivas solicitações sobre a qualidade da manga, fez-se necessária a utilização de técnicas para um melhoramento da qualidade e expansão da produção de manga. Nesse sentido, Bassoi et al. (2010) destacam a aplicação de reguladores de crescimento e o estresse hídrico, fazendo a predisposição das plantas ao florescimento no primeiro semestre e a colheita no segundo semestre de cada ano.

Outro fator relevante envolveu a mudança nas variedades produzidas de manga. Como apontam Oliveira et al. (2004), o cultivo da manga no Brasil se divide em duas fases. A primeira era em áreas esparsas, onde predominavam variedades como a Espada, e a segunda caracteriza-se pelo uso intensivo de tecnologias e variedades como Tommy Atkins, Haden e Palmer.

Entretanto, a escolha das variedades a serem produzidas pode ser influenciada por diversos fatores, tanto relacionados a fatores ligados à produção, quanto da fisiologia das próprias frutas ou do mercado consumidor. Nesse sentido, o objetivo deste trabalho é identificar os fatores que provocaram essas mudanças nos padrões de produção e consumo da manga no Brasil, especificamente na questão das variedades da fruta, e também identificar as tendências futuras para esse mercado.

Para identificar os fatores que provocaram mudanças nos padrões de produção e consumo da manga no Brasil, a metodologia escolhida para isso foi a do painel de especialistas. No caso específico deste trabalho, procurou-se ver a questão da escolha das variedades da manga, com foco no presente mas também no futuro, através de avaliações das variedades de manga em três conjuntos de variáveis: (1) Fatores relacionados à produção; (2) Fatores fisiológicos; e (3) Fatores relacionados ao mercado. 


\subsection{O MERCADO DA MANGA}

De acordo com a Pesquisa Agrícola Municipal do IBGE (IBGE, 2016), em 2014 o Brasil teve uma produção de 1.132.449 toneladas de manga. Como pode ser visto no Gráfico 1, houve um crescimento significativo no período 2001-2006, e desde então a produção brasileira está na faixa de 1.100 .000 a 1.200 .000 toneladas. Como apontam Treichel et al. (2016), no período de 2001 a 2014 houve um crescimento de aproximadamente 47,53\% no total da produção.

No cenário do comércio internacional, este crescimento também tem se firmado. Segundo Sabio et al. (2015b), o volume exportado de manga pelo Brasil em 2015 (janeiro a novembro) foi de 138,6 mil toneladas, batendo o recorde de exportação. Porém, segundo Ferraz (2005), as trocas mundiais de manga correspondem a uma pequena parcela do volume total produzido. No ano de 2013, segundo a FAO (2016), essa comercialização chegou a aproximadamente 2,79\% do total de mangas produzidas no mundo.

Quando se trata da manga, segundo dados da Pesquisa Agrícola Municipal do IBGE (IBGE, 2016), as regiões Nordeste e Sudeste têm, respectivamente, uma participação na área colhida e na quantidade produzida de 49.549 hectares e 784.692 toneladas para o Nordeste e 19.701 hectares e 334.881 toneladas para o Sudeste. Juntas, as duas regiões são responsáveis por aproximadamente $99 \%$ da produção brasileira.

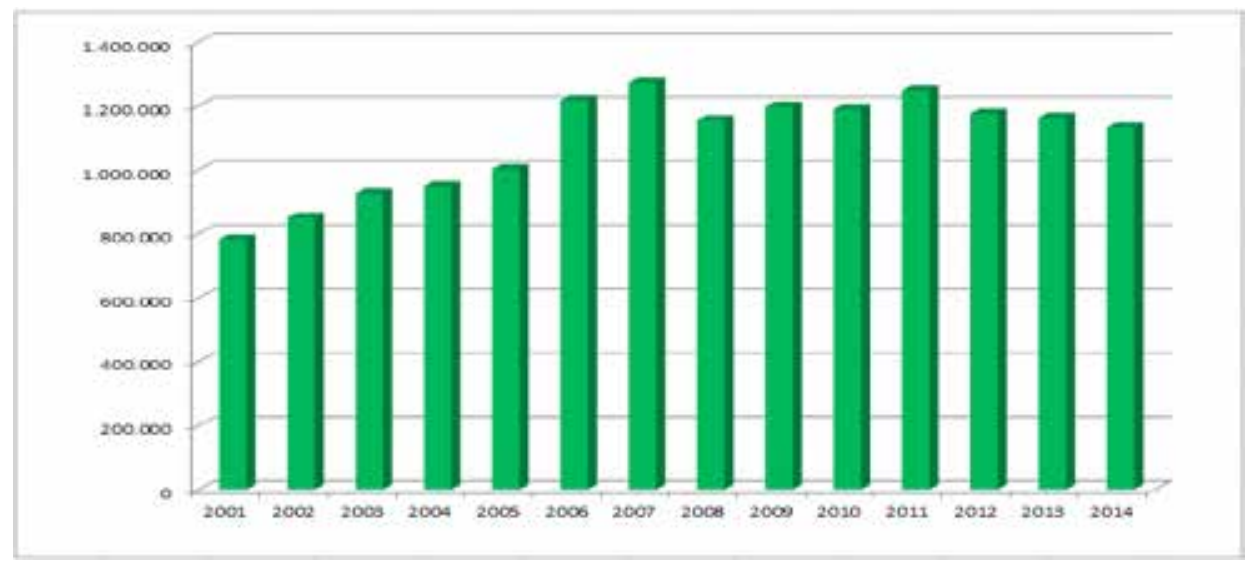

Gráfico 1. Produção brasileira de manga (ton)

Fonte: Baseado em dados da Pesquisa Agrícola Municipal do IBGE (IBGE, 2016). 
Também conforme a Pesquisa Agrícola Municipal do IBGE (IBGE, 2016), se destacam os Estados da Bahia (38\%), Pernambuco (19\%), São Paulo (18\%), Minas Gerais (10\%), Ceará (4\%) e Rio Grande do Norte (4\%), representando 93\% da produção da manga no Brasil. Nestes Estados, existem grandes centros de produção de manga, estando os principais concentrados nas microrregióes de Juazeiro (BA), Petrolina (PE), Livramento (BA) e Jaboticabal (SP). Juntas, as mesmas são responsáveis por uma participação de $60 \%$ na produção nacional desta cultivar.

Nesse sentido, o Vale do São Francisco (VSF), que compreende as microrregiões de Juazeiro e Petrolina, tem grande destaque, representando $84 \%$ das exportações brasileiras de manga em 2015, embarcando 131,5 mil toneladas e faturando US\$147 milhões. Dada a grande concorrência no mercado internacional, o Brasil concentra as suas vendas entre setembro e dezembro, período em que concorrentes como Equador e Peru saem do mercado. E tem ainda outro período de vendas, de janeiro a março (TREICHEL et al., 2016).

No ano de 2014, segundo o Aliceweb (2016), os principais destinos da manga exportada pelo Brasil foram os Países Baixos (41,95\% do volume), outros países da União Europeia (22,48\%), Estados Unidos (20,42\%), Reino Unido (7,69\%) e Canadá (4,13\%), estes correspondendo a 96,67\% da importação da manga brasileira.

Tendo em vista o cenário recente, segundo IBGE (2016) e Aliceweb (2016), a exportação de manga bateu recorde em 2014, tendo um valor de 138,6 mil toneladas (janeiro a novembro). Todavia, esse valor ainda é pouco expressivo quando relacionado com a quantidade produzida, podendo-se estimar que aproximadamente $12 \%$ do total de manga produzida no país foi exportada, sendo o restante direcionada ao mercado interno.

De acordo com Souza (2015), o mercado interno em 2013 ficou mais atrativo no Brasil. Conforme o estudo da Lima (2013), alguns fatores como a melhoria da renda dos brasileiros e as oscilações econômicas que atingiram os Estados Unidos e a Europa fizeram a quantidade de frutas destinadas ao mercado interno aumentar.

Outro fator que colabora para o crescimento da cultivar é o manejo da floração que, de acordo com Mouco e Albuquerque (2010), dá a oportunidade de se ter uma produção durante um ano todo e é um diferencial de maior interesse na exploração da mangueira. A mesma autora ainda ressalta que o manejo adequado da 
parte aérea, sem alterar a atividade metabólica, favorece a floração. Segundo Fonseca et al. (2006), a indução floral é uma prática de grande importância, pois propicia o aumento da produção e possibilita o deslocamento de colheitas para períodos de entressafra, ocasionando maior retorno econômico, sendo que existem métodos convencionais e orgânico de indução floral da mangueira.

Além dessas técnicas, um outro fator relevante envolveu a mudança nas variedades produzidas de manga.

\subsection{AS VARIEDADES DA MANGA}

Segundo Oliveira et al. (2004), o cultivo da manga no Brasil se divide em duas fases. A primeira era extensiva, em áreas esparsas, quintais e vales de pequenas propriedades. Já a segunda caracteriza-se por uso de tecnologias de irrigação, indução floral e variedades melhoradas. Na primeira fase predominava o cultivo de variedades como "Espada", "Coqueiro", "Ouro", etc. Estas estão perdendo espaço para variedades que são cultivadas em grandes áreas e possuem boa aceitação no mercado, como Tommy Atkins, Haden, Palmer, Keitt, Van Dyke, Kent, entre outras.

Entre as diversas variedades de manga cultivadas no Brasil, podem ser destacadas tanto as típicas da primeira era, como a Espada e a Rosa, quanto as da segunda, especialmente Tommy Atkins, Haden, Palmer, Keitt e Kent. Com base em Oliveira et al. (2004) e Matos (2000), as principais características dessas variedades são vistas no Quadro 1.

$\mathrm{Na}$ escolha das variedades, há uma série de fatores que podem ser considerados. Segundo Costa e Santos (2010), os produtores definem qual cultivar a ser escolhida comparando características como: produtividade, estabilidade de produção, facilidade com o manejo da planta e adaptação ao clima onde a cultivar está inserida. Outros fatores identificados pelos mesmos autores são o potencial produtivo na região considerada, a suscetibilidade às pragas, doenças e à deterioração após a colheita e, principalmente, à provável projeção de comercialização verificada a longo prazo.

Segundo Fonseca et al. (2006), podem ser selecionadas as variedades que aliam a alta produtividade a qualidades como a coloração atraente do fruto 
(de preferência vermelha), bom sabor, pouca fibra, resistência ao manuseio e ao transporte para mercados distantes, devendo ainda ser tolerantes à antracnose e não sujeitas à alternância de produção.

Fato é que os três principais segmentos da cadeia produtiva, sendo produtores, distribuidores e consumidores anseiam por variedades que atendam certas características. Para tanto, segundo Pinto, Neto e Guimarães (2011), os produtores querem cultivares que apresentem maior produtividade, estabilidade de produção e que sejam de fácil manejo nos tratos culturais e adaptadas às condições climáticas adversas da região para onde foi desenvolvida; os distribuidores anseiam por variedades que resistam ao manuseio e ao transporte e, por fim, os consumidores buscam manga de melhor qualidade, primeiro atraídos pela cor do fruto e depois pelo sabor.

Quadro 1. Características das principais variedades de manga

\begin{tabular}{|c|c|c|}
\hline Variedade & Principais Características & Aparência \\
\hline $\begin{array}{l}\text { Tommy } \\
\text { Atkins }\end{array}$ & $\begin{array}{l}\text { Frutos médios a grandes (até } 13 \mathrm{~cm} \text { de comprimento, } 400 \mathrm{~g} \text { a } \\
600 \mathrm{~g} \text { ), com uma cor da casca predominantemente avermelhada, } \\
\text { resistentes ao manuseio e ao transporte, de casca grossa, lisa. } \\
\text { Polpa de textura firme, coloração amarelo-escura, de sabor } \\
\text { agradável, Brix de } 17^{\circ} \text { e poucas fibras. Produção natural de meia- } \\
\text { estação, de outubro a janeiro, apresentando resistência mediana } \\
\text { à antracnose sendo, no entanto, uma das mais sensíveis ao } \\
\text { colapso interno dos frutos. }\end{array}$ & \\
\hline Haden & $\begin{array}{l}\text { Genitora da Tommy Atkins, precoce como tal. Suscetível à } \\
\text { antracnose, malformação floral, deterioração após a colheita, } \\
\text { transporte, manuseio e ao colapso interno. Frutos de tamanho } \\
\text { intermediário e pesam aproximadamente } 700 \text { gramas, com } \\
\text { atrativa coloração avermelhada, polpa com coloração amarelo } \\
\text { intenso e consistente, suave e moderada quantidade de fibras } \\
\text { e } 21^{\circ} \text { Brix. }\end{array}$ & \\
\hline Palmer & $\begin{array}{l}\text { Os frutos são grandes }(15 \mathrm{~cm} \text { de comprimento, até } 900 \mathrm{~g}) \text {, de } \\
\text { cor laranja amarelada com laivos vermelho-brilhante. A polpa é } \\
\text { bem amarelada, tem pouca fibra, é firme, com aroma suave e } 19^{\circ} \\
\text { de Brix. A maturação é tardia. Aceitação crescente no mercado } \\
\text { consumidor. }\end{array}$ & \\
\hline
\end{tabular}




\begin{tabular}{|c|c|c|}
\hline Variedade & Principais Características & Aparência \\
\hline Keitt & $\begin{array}{l}\text { Seus frutos são grandes (até } 15 \mathrm{~cm} \text { de comprimento, } 600 \mathrm{~g} \mathrm{a} \\
800 \mathrm{~g} \text { ), de casca amarelo-esverdeada, geralmente com laivos } \\
\text { leves cor-de-rosa, polpa de tom amarelo-intenso, sem fibras, } \\
\text { firme, sucosa, doce e com Brix de } 21^{\circ} \text {. É resistente à antracnose } \\
\text { e apresenta boa resistência ao transporte. }\end{array}$ & \\
\hline Kent & $\begin{array}{l}\text { O fruto é grande ( } 13 \mathrm{~cm} \text { de comprimento, } 600 \mathrm{~g} \text { a } 750 \mathrm{~g} \text { ), de } \\
\text { casca entre verde-claro e amarelo, laivos carmesim, adquirindo } \\
\text { tom avermelhado com o amadurecimento. A polpa é amarela- } \\
\text { alaranjada, apresenta um Brix de } 19^{\circ} \text {, sem fibra, aromática e } \\
\text { sucosa. A maturação é tardia. É suscetível às principais doenças. }\end{array}$ & \\
\hline Espada & $\begin{array}{l}\text { Frutos com coloração verde ou um equilíbrio entre matizes } \\
\text { amarelados e esverdeados, casca lisa e espessa, polpa amarelada, } \\
\text { tamanho intermediário, pesando até aproximadamente } 300 \\
\text { gramas, apresenta uma significativa porcentagem de fibras e } 17 \text { a } \\
20^{\circ} \text { de Brix. A "Espada" normalmente produz duas vezes por ano, } \\
\text { sendo muito requerida pelo consumidor brasileiro em virtude } \\
\text { do sabor. Ela expressa rusticidade e precocidade, possibilitando } \\
\text { a antecipação do investimento econômico, e resistência à } \\
\text { antracnose, à morte descendente e ao colapso interno. }\end{array}$ & \\
\hline Rosa & $\begin{array}{l}\text { Frutos que pesam entre } 300 \text { e } 350 \text { gramas, de coloração amarelada } \\
\text { ou rosada a avermelhada, casca lisa, espessa e aderente, polpa } \\
\text { bem amarela, } 14 \text { a } 16^{\circ} \text { Brix e uma quantidade expressiva de } \\
\text { fibras. Considerada variedade brasileira. Esta variedade possui } \\
\text { característica vigorosa, porém crescimento lento, porte médio, } \\
\text { maior sujeição à antracnose, produtividade inferior e alternância } \\
\text { de produção. Em contrapartida, a variedade possui intenso } \\
\text { processo de florescimento e reponde bem à indução floral. } \\
\text { Considerada como variedade tardia e moderada em relação à } \\
\text { morte descendente. É muito importante e conhecida, logo, muito } \\
\text { comercializada, principalmente para o consumo in natura. }\end{array}$ & \\
\hline
\end{tabular}

Fonte: Baseado em Oliveira et al. (2004) e Matos (2000).

Diversos estudos, como Oliveira et al. (2004), Fonseca et al. (2006) e Pinto, Neto e Guimarães (2011), identificam características almejadas para a obtenção de uma cultivar ideal, como uma planta que produza em média 40 t/ha em densidade 476 plantas/ha, que tenha produção precoce e regular, seja resistente às principais doenças e pragas, frutos com peso de $400 \mathrm{~g}$ a $500 \mathrm{~g}$, de forma ovalada, tendo ainda, 
quando madura, uma coloração da casca vermelha a vermelha-arroxeada brilhante, a polpa na cor laranja intenso, com pouca fibra ou sem, brix acima de $18 \%$ e ligeiramente ácida com outras boas qualidades organolépticas (odor, textura), livres de desordens fisiológicas, shelf-life entre 3 e 4 semanas e resistência ao transporte.

Nesse sentido, outros estudos também apontam fatores que influenciaram nessa mudança no mercado da manga, além dos já mencionados. Matos (2000) destaca também a resistência ao manuseio e ao transporte para mercados distantes, a regularidade de produção, a resistência a doenças (como malformação floral, antracnose e botriodiplodia) e a baixa incidência de colapso interno de polpa. Segundo Sabio et al. (2015a), a aparência da fruta é de fundamental importância, não podendo haver pintas ou rachaduras.

A facilidade do manejo pode variar conforme a variedade, já que algumas possuem resistências às pragas e doenças. Exemplo disso é o colapso interno, que é mais recorrentes nas variedades Tommy Atkins, Kent, Irwin e Keitt, se postas em comparação com a Espada, Coquinho e Rosinha. A malformação floral também é um problema que comumente ocorre em plantas como a Tommy Atkins e raramente na Haden (LOPES; OLIVEIRA; FREITAS, 2003).

No caso da industrialização, segundo Filgueiras (2000), a dependência em relação à variedade Tommy Atkins é um obstáculo a ser superado para o sucesso do mercado da manga no Brasil, assim como a utilização de variedades menos fibrosas e mais ricas em sabor. Essa afirmação é enfatizada por Ramos, Souza e Benevides (2004), que relatam o insucesso da industrialização da manga, devido ao interesse na produção de variedades exportáveis, e deixando de lado variedades que são ideais para indústria.

Segundo Costa (2006), a manga é geralmente transportada diversas vezes, até chegar ao local de venda. Nas exportações, as mangas são transportadas por diversos modais, como o rodoviário até os portos ou aeroportos, de onde são transportadas novamente por via marítima ou via aérea até o país importador, sendo ainda utilizando o transporte rodoviário até o armazém refrigerado do importador ou do cliente varejista. Sendo assim, a variedade de manga escolhida para transporte precisa ter uma maior resistência para que não chegue ao local de destino com injúrias, ou seja, com a qualidade afetada. 
No caso da preferência dos consumidores, de acordo com Correia e Araujo (2010), de modo geral, as mangas prediletas do mercado internacional são as coloridas. Frutos de tons verdes ainda possuem problemas de comercialização. Segundo o estudo realizado por Araújo e Gárcia (2012), a variedade Tommy Atkins tem grande espaço no mercado da União Europeia, que é o maior local de destino da manga do Brasil, porque esta cultivar é a que melhor suporta o translado por via marítima e que tem um período mais longo de prateleira.

Em relação às preferências dos consumidores, o mercado europeu apresenta particularidades. Países do Norte e Alemanha preferem a Tommy Atkins, devido a caracteríticas como coloração e tamanho. A França e países do Sul preferem variedades como a Kent, Keitt e Haden, em razão do sabor mais consistente, fruto do representativo percentual de sólidos solúveis e baixo teor de fibras, o que facilita a ingestão da fruta. No mercado norte-americano observa-se preferência pela Tommy Atkins, sendo esta a variedade mais exportada pelo Brasil (FAVERO, 2008).

De acordo com o estudo feito por Pay (2009), os consumidores europeus preferem uma manga amarela escura em que se desenvolve uma coloração avermelhada rosa. Casca vermelha é considerado uma necessidade em mangas embarcados para mercados do Norte, embora a qualidade pode ser inferior ao de cultivares que não sejam atraentes. Ainda segundo o estudo, nota-se que os consumidores nos Estados Unidos tendem a confundir maturação com a cor, preferindo mangas de casca vermelha do que variedades não vistosas, tal fato reforça a preferência do mercado norte-americano pela variedade Tommy Atkins.

\section{MATERIAIS E MÉTODOS}

Para identificar os fatores que provocaram mudanças nos padrões de produção e consumo da manga no Brasil, especificamente na questão das variedades da fruta, e expor as perspectivas atuais e futuras dessa questão, além da pesquisa bibliográfica, é necessário investigar essa questão sobre vários pontos de vista.

A metodologia escolhida para isso foi a do painel de especialistas. Essa metodologia é utilizada em áreas como a da Saúde, como em Marchon e Mendes 
Júnior (2015); Ciências Humanas e Sociais Aplicadas (PINHEIRO; FARIAS; ABE-LIMA, 2013); e Ciências Agrárias (FONTES; PIRES; SUJII, 2002).

Painel de especialistas é uma técnica de pesquisa empregada em Psicologia, Administração e Ciências Sociais em geral, geralmente em investigações que incluem mais de uma técnica de pesquisa, de acordo com concepções multimetodológicas. $O$ especialista representa uma perspectiva bem específica sobre o assunto, a ser integrada com outras visões sobre o tema, e não implicando em palavra final ou definitiva a respeito do mesmo. A "especialidade" de seus integrantes pode se referir aos ambientes ou situações de interesse para a pesquisa, pessoas investigadas ou aos fenômenos (ou conceitos) a serem tratados (PINHEIRO; FARIAS; ABE-LIMA, 2013).

Ainda segundo os mesmos autores, o painel de especialistas pode fazer parte de um projeto de pesquisa em dois momentos distintos: como parte de uma fase preliminar, em que contribui para o estabelecimento de bases para a investigação, ou como parte da coleta de dados propriamente dita, como estratégia única de investigação ou combinada com outras.

No caso específico deste trabalho, procurou-se ver a questão da escolha das variedades da manga, com foco no presente mas também no futuro, através de avaliações das variedades de manga em três conjuntos de variáveis: (1) Fatores relacionados à produção; (2) Fatores fisiológicos; e (3) Fatores relacionados ao mercado.

Os componentes do painel foram pesquisadores da Embrapa Semiárido, especialistas, especificamente, nas áreas de manejo da produção, germoplasma, pós colheita e economia/mercado. Nesse caso, o painel de especialistas foi combinado um roteiro de avaliação, buscando fazer uma análise comparativa das variedades da manga, compreender o processo de mudança das variedades e identificar tendências futuras relacionadas a essa questão.

Devido às características deste trabalho, este pode ser classificado como uma pesquisa explicativa e descritiva. Segundo Prodanov e Freitas (2013), as pesquisas descritivas transcrevem os fatos que o pesquisador observa, sem realizar nenhuma interferência nos mesmos, possuindo como função observar, registrar e analisar os dados. Já as pesquisas explicativas, conforme Gil (2008), têm por objetivo principal a identificação de fatores que possam contribuir para a ocorrência de determinado fenômeno, explicando os motivos e porquês do acontecimento estudado. 
Quanto à metodologia da análise dos dados, foi utilizada a análise de conteúdo. Esta se caracteriza por ser composta por várias técnicas, objetivando a descrição do conteúdo que foi coletado. Esta metodologia possui procedimentos sistemáticos que visam levantar indicadores que permitem a realização de deduções de conhecimentos (CAVALCANTE; CALIXTO; PINHEIRO, 2014).

\section{RESULTADOS E DISCUSSÃO}

Para aprofundar a análise comparativa entre as variedades, foram definidos três grupos de fatores, cada um com uma série de variáveis relacionadas. As variedades (Tommy Atkins, Haden, Palmer, Keitt, Kent, Espada e Rosa) foram comparadas entre si em cada uma destas variáveis.

Como citado anteriormente, o painel foi composto por pesquisadores da Embrapa Semiárido. Estes foram escolhidos visando representar diferentes especialidades relacionadas à produção (desenvolvimento genético, manejo da produção, pós-colheita) e ao mercado. Dessa forma, buscou-se trazer a visão de diferentes aspectos envolvidos com a cultura da manga.

Quadro 2. Fatores para comparação entre as variedades

\begin{tabular}{|c|l|}
\hline $\begin{array}{c}\text { Fatores } \\
\text { relacionados } \\
\text { à produção }\end{array}$ & $\begin{array}{l}\text { Tecnologias de produção (irrigação/manejo); Tecnologias de indução floral; } \\
\text { Adaptação às condiçóes climáticas locais; Facilidade de manejo; Produtividade } \\
\text { (ton/ha); Custo de produção; Resistência a pragas e doenças; Densidades de } \\
\text { árvores por hectare }\end{array}$ \\
\hline $\begin{array}{c}\text { Fatores } \\
\text { fisiológicos }\end{array}$ & $\begin{array}{l}\text { Aspecto visual (aparência); Cor da casca; Cor da polpa; Peso/tamanho do fruto; } \\
\text { Teor de açúcar ( }{ }^{(} \text {Brix); Custo de produção; Presença ou ausência de fibras; } \\
\text { Uniformidade de tamanho }\end{array}$ \\
\hline $\begin{array}{c}\text { Fatores } \\
\text { relacionados } \\
\text { ao mercado }\end{array}$ & $\begin{array}{l}\text { Resistência ao manuseio e transporte; Tempo de prateleira (shelf life); } \\
\text { Requisitos da indústria alimentícia; Requisitos das redes varejistas ou } \\
\text { consumidor do mercado externo; Requisitos das redes varejistas ou consumidor } \\
\text { do mercado interno }\end{array}$ \\
\hline
\end{tabular}

Fonte: Autoria própria.

Os dados coletados foram estruturados de forma a compor uma escala numérica de sobreposição. Essa escala buscou comparar as características de uma 
variedade em relação às outras. Para facilitar a apresentação e a comparação entre variedades, esses dados foram utilizados para gerar gráficos de radar, que revelam de que forma as variedades se posicionam frente às suas concorrentes.

O Gráfico 2 mostra que as variedades, no caso dos fatores relacionados à produção, possuem um comportamento similar, não possuindo, assim, diferenças que pudessem justificar a escolha de uma variedade específica.

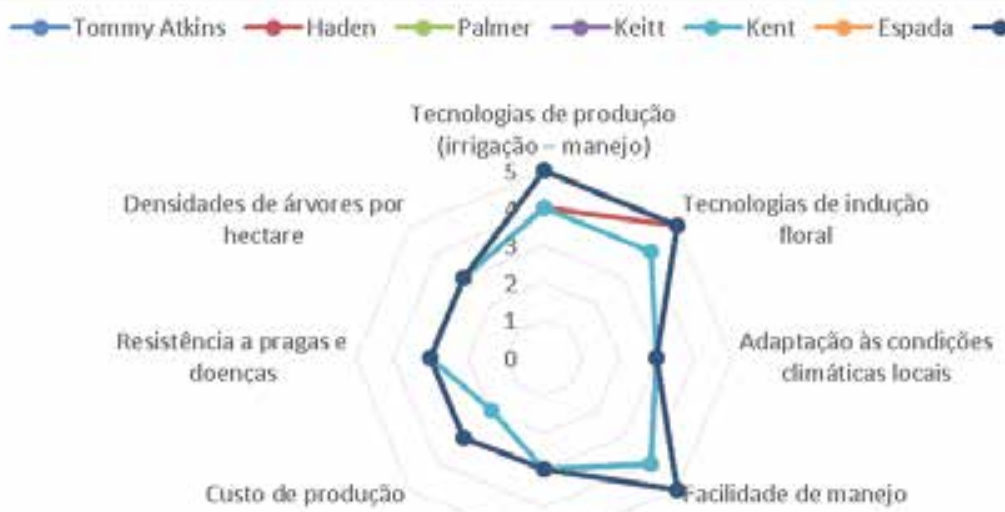

Produtividade (ton/ha).

Gráfico 2. Comparação das variedades de manga relacionada a fatores ligados à produção Fonte: Resultados do painel de especialistas.

A partir das avaliações dos especialistas, pôde-se inferir que:

- Quanto às tecnologias de produção: Esse fator apresentou semelhança de resultados nas variedades como: Tommy Atkins, Palmer, Kent, Espada e Rosa. Apresentam avaliações comparativamente piores as variedades Keitt e Haden, sendo esta última por problemas de incompatibilidade. Segundo os pesquisadores, as tecnologias de produção utilizadas são comuns para todas as variedades, e estas por sua vez respondem de forma similar. No caso das variedades como a Espada e Rosa, apesar de não possuírem plantios em larga escala na região, segundo o pesquisador responsável pela área de germoplasma, a resposta das cultivares em alguns testes realizados em campo se mostrou similar. 
- Quanto às tecnologias de indução floral: A maioria das cultivares possuem comportamento similar quanto à resposta a indução floral, exceto a Kent.

- Quanto às adaptações às condições climáticas locais: Todas as variedades apresentam adaptação às condições do clima da região, principalmente a Rosa e Espada, já que estas tratam-se de cultivares nacionais. Porém, segundo pesquisadora na área de manejo, a Haden em períodos muito quentes pode sofrer de queda de produtividade.

- Quanto à facilidade de manejo: De forma geral, a partir das respostas, pôde-se observar que o manejo que é realizado para as variedades é uniforme para todas, possuindo leves diferenças devido a particularidades em variedades como Haden e Kent.

- Quanto à produtividade: Segundo os pesquisadores, a produtividade da mangueira é proporcional à intensidade de adubação e manejo. Sendo assim, as variedades seriam equivalentes quando submetidas a um mesmo tratamento.

- Quanto ao custo de produção: O custo de produção varia pouco entre as cultivares. Segundo a pesquisadora responsável pela área de manejo e pelo pesquisador da área de germoplasma, a Kent apresenta um custo diferente das outras, já que esta exige maior aplicação de Paclobutrazol (PBZ), que visa regular o crescimento vegetativo da mangueira.

- Quanto à resistência a pragas e doenças: Existem diferenças entre as variedades quanto a resistência, porém a forma correta de manejar a cultura pode proporcionar uma similaridade no comportamento das diferentes cultivares.

- Quanto à densidade de árvores por hectare: O adensamento do pomar, segundo os pesquisadores, é equivalente a todas as cultivares, cabendo adaptar o manejo à densidade escolhida.

O Gráfico 3 retrata as diferenças entre as características fisiológicas das variedades. Logo, essa diferenciação pode indicar que se a tomada de decisão para escolha da variável for realizada a partir de critérios relacionados a atributos da fruta, algumas variedades irão sobressair em relação às outras.

A partir dos resultados obtidos no painel, o comportamento das variedades se mostrou da seguinte forma:

- Quanto ao aspecto visual (aparência): O aspecto visual de variedades 
como Tommy Atkins e Palmer foi considerado superior às outras variedades. A Palmer, por possuir uma coloração vermelha, agrada mais o consumidor. Cabe ressaltar que a Keitt naturalmente não fica com tons avermelhados, o que a desfavorece frente às demais. Cultivares como Espada e Rosa não têm um aspecto visual tão desejável, comparado às outras variedades.

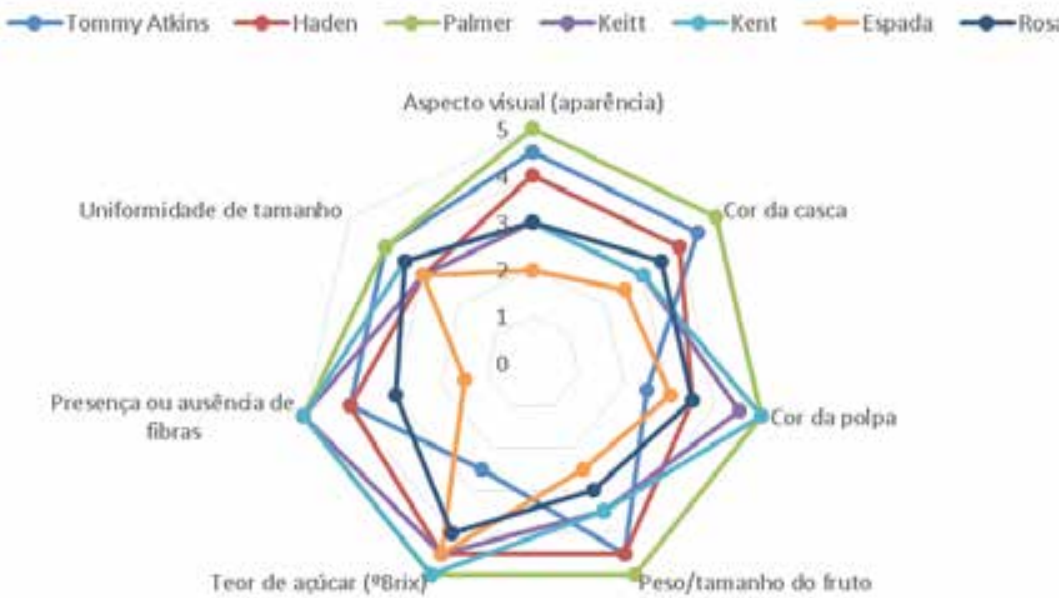

Gráfico 3. Comparação das variedades de manga relacionada a fatores fisiológicos Fonte: Resultados do painel de especialistas.

- Quanto à cor da casca: $\mathrm{O}$ aspecto visual da manga é principalmente avaliado pela coloração da sua casca. As avaliações nesse quesito foram similares às dadas na aparência. Foi ressaltado pelos pesquisadores o fato de que o consumidor tem preferência por frutas de coloração avermelhada, logo, variedades como a Espada, por possuir coloração esverdeada, não atendem às preferências de modo geral. O consumo da mesma está atrelado ao sabor e a fatores culturais.

- Quanto à cor da polpa: O consumidor possui preferência por variedades que possuem cor da polpa mais alaranjada. Apesar da coloração atraente da casca da Tommy, esta, frente a outras variedades, não possui uma cor da polpa equivalente às outras. A Palmer se mostrou melhor do que a Keitt. Espada e Rosa se igualam na avaliação deste quesito. 
- Quanto ao peso/tamanho do fruto: No que se refere a este quesito, as avaliações dos pesquisadores indicaram que a Palmer, Tommy Atkins e Haden são as que possuem melhor avaliação, seguidas por Keitt e Kent, e, por último, variedades como Espada e Rosa. Segundo a pesquisadora de pós-colheita, as notas da Keitt e Kent são equivalentes às da Espada, porém diferem as razões para isso. Enquanto o tamanho avantajado da Keitt e Kent prejudicam sua aceitação, o tamanho reduzido da espada também causa esse efeito.

- Quanto ao teor de açúcar (Brix): No que se refere ao teor de açúcares das variedades, a Tommy é a que mais peca frente às outras variedades. Próxima a ela, se encontra a Rosa. As melhores avaliações quanto a este quesito foram da Palmer e da Kent, seguidas de Espada, Keitt e Haden com avaliações equivalentes.

- Quanto à presença ou ausência de fibras: As avaliações da presença de fibras por variedades indicaram que as cultivares Palmer, Keitt e Kent são as mais bem avaliadas nesse quesito, já que existe preferência pela ausência das fibras. Variedades como Tommy Atkins, Haden e Rosa, apesar de não receberem uma avaliação melhor que as outras, se encontram em um patamar mediano. A pior avaliação foi dada à Espada, pois esta possui uma maior quantidade de fibras.

- Quanto à uniformidade de tamanho: Variedades como Tommy Atkins e Palmer possuem uma melhor avaliação neste quesito, seguida por Haden, Keitt e Kent. A espada possui uma maior variação nos tamanhos dos frutos, isso devido às técnicas de manejo que ainda são ausentes quando se trata desta cultivar. A Rosa possui uma avaliação mediana.

Por fim, o Gráfico 4 apresenta as diferenças de avaliação entre as variedades em características relacionadas à distribuição, industrialização, comercialização e consumo. Mais especificamente, em relação aos seguintes aspectos:

- Quanto à resistência ao manuseio e transporte: A variedade Tommy Atkins foi considerada como a mais resistente ao transporte e manuseio. Já a cultivar Haden foi descrita como vulnerável, por não apresentar uma resistência tão boa quanto as demais. Variedades como Palmer, Keitt, Kent e Rosa tiveram uma avaliação equivalente, sendo elas, medianas. A variedade Espada, por comumente não receber condições de manuseio similares às demais, se encontra em um patamar mediano, porém foi enfatizado que a mesma possui uma casca mais grossa e tem potencial, 
desde que receba os tratamentos corretos, de apresentar uma boa resistência ao manuseio e transporte.

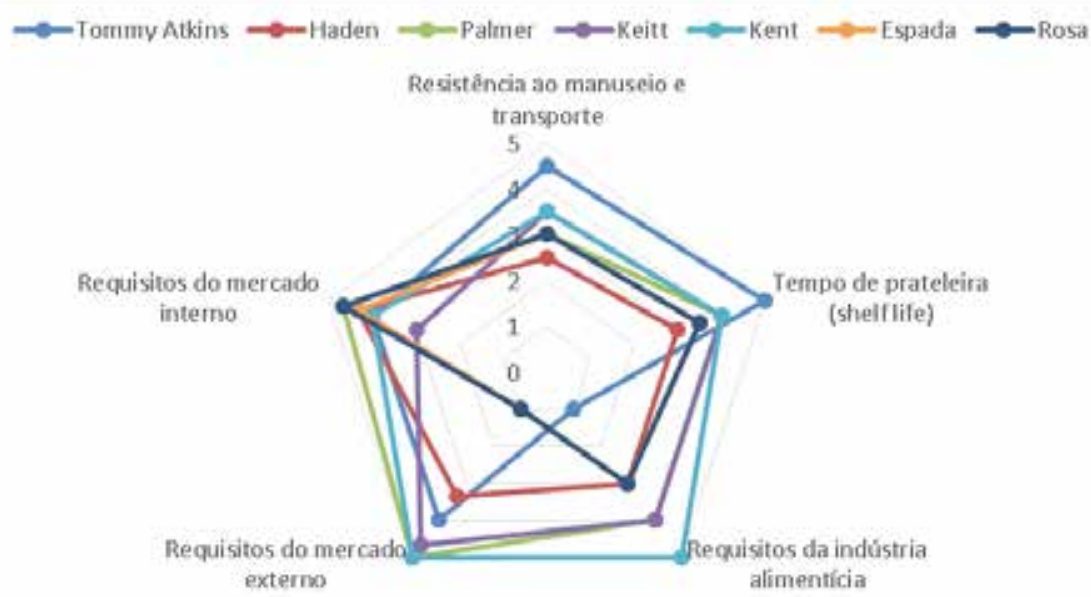

Gráfico 4. Comparação das variedades de manga relacionada a fatores ligados ao mercado Fonte: Resultados do painel de especialistas.

- Quanto ao tempo de prateleira (shelf life): De modo geral, a Tommy Atkins obteve a melhor avaliação neste quesito, fator esse correlacionado com suas características de resistência ao manuseio. As variedades Palmer, Keitt e Kent possuem uma avaliação similar. Já as variedades Palmer, Espada e Rosa se encontram no mesmo patamar. Comparativamente, a Haden tem o pior desempenho nesse quesito.

- Quanto aos requisitos da indústria alimentícia: A avaliação neste quesito seguiu por um viés das características da fruta, pois de modo geral nenhuma das cultivares citadas são utilizadas de forma intensiva na indústria, somente em algumas proporções ao lado de outras variedades. A Kent foi a variedade que melhor foi avaliada. Já a Tommy Atkins, devido ao sabor não ser tão valorizado quanto às outras, recebeu uma pior avaliação.

- Quanto aos requisitos do mercado externo: Quanto às exigências do mercado externo, as variedades que apresentaram melhores requisitos foram 
a Palmer e Kent. A Espada e Rosa não possuem as características exigidas para a exportação. A Keitt e Haden receberam uma avaliação similar. Apesar da Tommy não receber a melhor avaliação, devido às suas características pós-colheita e preferências de certos mercados, ela recebeu uma boa avaliação.

- Quanto aos requisitos do mercado interno: A avaliação dos requisitos quanto ao mercado externo deve obedecer algumas particularidades que são decorrência das exigências das diferentes regiões. A Palmer é bastante consumida na região Sudeste, sendo a Rosa e Espada mais direcionada ao Nordeste. De modo geral a avaliação de todas as cultivares variou pouco, apresentando notas similares, porém a Keitt obteve uma nota inferior.

Os resultados obtidos apontaram que, no caso dos fatores relacionados à produção, não houve diferenças significativas entre as variedades, indicando assim que não estão nesta fase da cadeia os fatores determinantes para a escolha de uma variedade em detrimento à outra. Porém, no caso das características fisiológicas e os fatores relacionados ao mercado, há diferenças substanciais que dariam suporte a escolha de determinadas variedades. No caso das variáveis voltadas para exportação, os resultados indicam a maior influência dos aspectos pós-colheita, fazendo destes os mais considerados na avaliação de preferência da cultivar.

As informações colhidas no painel convergem para um mesmo direcionamento sobre as mudanças na escolha da variedade da manga. Segundo as mesmas, o Brasil entrou no circuito de exportação usando basicamente Keitt, Kent, Tommy Atkins e Haden. Destas, a que mais facilmente se adaptou às condições do semiárido e ao sistema de produção e pós-colheita foi a Tommy Atkins. Porém, esta variedade não possui um sabor tão valorizado quanto as suas concorrentes, fazendo com que mercados como o europeu começassem a gostar mais de variedades como Keitt e Kent, proporcionando o aumento das áreas cultivadas destas variedades. Por sua vez, a Haden tem dificuldade de adaptação as condições climáticas da região, a produtividade é baixa, a vida pós-colheita é curta e a conservação é mais difícil, logo o panorama desta variedade não é tão promissor frente às demais.

Portanto, o fator decisivo na mudança do cultivo de determinadas variedades foi o estímulo à exportação. À medida em que o produtor passou a enxergar uma oportunidade em ser inserido no comércio internacional, passou a se adequar às 
exigências que o mesmo impunha. As produções de manga no Brasil que visam o mercado externo precisam produzir dentro de uma janela de mercado, que se inicia em julho e vai até setembro. Para produzir corretamente nessa época, é necessário usar uma variedade que responda bem às técnicas de manejo, que suporte o tratamento pós-colheita, transporte e que sejam atrativas visualmente. Neste apanhado de quesitos, a variedade Tommy Atkins prevaleceu.

As variedades tradicionais, como Espada e Rosa, possuem uma demanda fortemente ligada à cultura. Ao longo dos anos estas perderam espaço, pois a produção de mangas em escala comercial buscou atender às exigências do mercado externo, assim os excedentes da produção foram canalizados ao mercado interno, concorrendo diretamente com estas variedades tradicionais.

\section{CONSIDERAÇÕES FINAIS}

O presente trabalho teve por objetivo identificar as variáveis que determinam mudanças nos padrões de consumo da manga no Brasil, considerando especificamente a questão das variedades da fruta. O painel com representativos pesquisadores da cadeia produtiva da manga propiciou a geração de importantes informações para o estudo. Este, por sua vez, pode contribuir para o enriquecimento dos estudos da área, na tomada de decisões dos produtores e na descrição de elementos particulares da cadeia produtiva da manga no país.

Foi constatado que o cultivo da manga em proporções comerciais teve como motivador a possibilidade da exportação da fruta. Baseados nisto, os produtores se adaptaram às exigências que eram ditadas pelo mercado internacional, optando por variedades que possuíam características essenciais para a exportação. Características estas relacionadas a fatores pós-colheita, como resistência ao manuseio e transporte. Variedades como Tommy Atkins ganharam espaço por possuir estas características, e com a exportação consolidada, ocorreu diversificação no cultivo de outras variedades que possuíam fatores como sabor, teor de açúcares e aspecto visual mais relevantes.

As variedades tradicionais enfrentam, portanto, a concorrência do excedente de produção das mangas que não são exportadas. As perspectivas futuras 
indicam uma estabilização das variedades, com ressalvas à Palmer, que apresenta aumento significativo de sua oferta. As variedades Espada e Rosa continuarão sendo demandadas, porém, restrita a fatores culturais e nichos de mercado. A mudança dependerá da diversificação dos produtores, caso isso não ocorra, o atual cenário se permanecerá estável.

\section{REFERÊNCIAS}

ALICEWEB. Aliceweb2. Disponível em: < http://aliceweb.mdic.gov.br/> Acesso em: 15 jul. 2016.

ARAÚJO, J. L. P.; GARCÍA, J. L. L. Estudo do mercado de manga na União Européia. Petrolina: Embrapa Semiárido, 2012. (Documento técnico-científico).

BASSOI, L. H. et al. Irrigação. In: MOUCO, M. A. (Ed.). O cultivo da mangueira. Petrolina: Embrapa Semiárido, 2010.

CAVAlCANTE, R. B.; CAliXTO, P.; PINHEIRO, M. M. K. Análise de conteúdo: considerações gerais, relações com a pergunta de pesquisa, possibilidades e limitações do método. Informação \& Sociedade: Estudos, João Pessoa, v. 24, n. 1, p. 13-18, jan./abr. 2014.

CORREIA, R. C.; ARAÚJO, J. L. P. Custos e rentabilidade. In: MOUCO, M. A. (Ed.) O cultivo da mangueira. Petrolina: Embrapa Semiárido, 2010.

CORREIA, R. C.; ARAÚJO, J. L. P. Mercado. In: MOUCO, M. A. (Ed.) O cultivo da mangueira. Petrolina: Embrapa Semiárido, 2010.

COSTA, J. G.; SANTOS, C. A. F. Cultivares. In: MOUCO, M. A. (Ed.). O cultivo da mangueira. Petrolina: Embrapa Semiárido, 2010.

COSTA, D. L. P. Estratégias de gestão da cadeia de suprimentos da manga brasileira destinada ao mercado externo. 2006. 192f. Dissertação (Mestrado) Escola Politécnica, Universidade de São Paulo, 2006. 
FAVERO, L. A. A Cultura da Manga no São Francisco: Posicionamento, Limites, Oportunidades e Ações Estratégicas. Fortaleza: Banco do Nordeste do Brasil, 2008. $232 \mathrm{p}$.

FERRAZ, M. S. Perspectivas de mercado: produção e consumo de manga. In: SIMPÓSIO DE MANGA DO VALE DO SÃO FRANCISCO, 1., 2005. Anais... Juazeiro: Embrapa Semi-Árido. 2005.

FILGUEIRAS, H. A. C. Manga pós colheita. Brasília: Embrapa Comunicação para Transferência de Tecnologia, 2000. 40p.

FONTES, E. M. G.; PIRES, C. S. S.; SUJII, E. R. Painel de especialistas sobre impactos potenciais ao meio ambiente do algodão geneticamente modificado resistente a insetos. Brasília: Embrapa Recursos Genéticos e Biotecnologia, 2002.

FONSECA, N. et al. A cultura da manga. 2. ed. Brasília: Embrapa Informação Tecnológica, 2006. 63p.

FAO. Food and Agriculture Organization of the United Nations Statistics Division. FAOSTAT. 2016. Disponível em: < http://faostat3.fao.org/browse/Q/*/E > . Acesso em: 20 jul. 2016.

GIL, A. C. Métodos e técnicas de pesquisa social. 6. ed. São Paulo: Atlas, 2008.

IBGE. Pesquisa Agrícola Municipal. Disponível em: < http://www.sidra.ibge.gov. br >. Acesso em: 15 jul. 2016.

LIMA, J. R. F. Exportações de Manga produzida no submédio do Vale do São Francisco no Período de 2003-2012. Petrolina: Embrapa Semiárido, 2013.

LOPES, P. R. C.; OLIVEIRA, V. H.; FREITAS, J. A. D. Produção integrada de frutas. Fortaleza: Instituto Frutal, 2003. 160p.

MATOS, A. P. Manga - produção: aspectos técnicos. Brasília: Embrapa Comunicação para Transferência de Tecnologia, 2000. 63p. 
MARCHON, S. G.; MENDES JÚNIOR, W. V. Tradução e adaptação de um questionário elaborado para avaliar a segurança do paciente na atenção primária em saúde. Cad. Saúde Pública, Rio de Janeiro, v. 31, n. 7, p. 1395-1402, 2015.

MOUCO, M. A. C.; ALBUQUERQUE, J. A. S. Manejo da floração. In: MOUCO, M. A. (Ed.). O cultivo da mangueira. Petrolina: Embrapa Semiárido, 2010.

OLIVEIRA, A. R. D. et al. Cultivo da mangueira. Petrolina: Embrapa Semiárido, 2004. 111p.

PAY, E. The Market for organic and fair-trade mangoes: increasing incomes and food security of small farmers in West and Central Africa through exports of organic and fair-trade tropical products. Food And Agriculture Organization of The United Nations, Rome, 2009.

PINHEIRO, J. Q.; FARIAS, T. M.; ABE-LIMA, J. Y. Painel de especialistas e estratégia multimétodos: reflexões, exemplos, perspectivas. Psico, v. 44, n. 2, p. 184-192, abr./ jun. 2013.

PINTO, A. C. Q.; LIMA NETO, F. P.; GUIMARÃES, T. G. Estratégias de melhoramento genético da manga visando atender a dinâmica de mercado. Revista Brasileira de Fruticultura, São Paulo, v. 33, p. 64-72, 2011.

PRODANOV, C. C.; FREITAS, E. C. Metodologia do trabalho científico: métodos e técnicas da pesquisa e do trabalho acadêmico. 2. ed. Novo Hamburgo: Feevale, 2013. 277p.

RAMOS, A. M.; SOUSA, P. H. M.; BENEVIDES, S. A. Tecnologia da industrialização da manga. In: ZAMBOLIM, L. (Org.). Manga: produção integrada, industrialização e comercialização. Viçosa: Universidade Federal de Viçosa, 2004, p. 571-604.

SABIO, R. P. et al. A vez dos HFS feios. Hortifruti Brasil, n. 148, ago. 2015a.

SABIO, R. P. et al. Manga é destaque nas exportações pelo $2^{\circ}$ ano consecutivo. Hortifruti Brasil, n. 152, 2015b. 
SEBRAE. Agronegócio: fruticultura. Boletim de Inteligência, out. 2015.

SILVA, P. C. G.; COELHO, R. C. Socioeconomia. In: MOUCO, M. A. (Ed.). O cultivo da mangueira. Petrolina: Embrapa Semiárido, 2010.

SOUZA, S. F. Mecanismos de transmissão de preços e parcelas de mercado: uma análise sobre as exportações brasileiras de manga. 2015. 86f. Dissertação (Mestrado) - Curso de Pós-Graduação em Economia, Centro de Ciências Sociais Aplicadas, Universidade Federal do Rio Grande do Norte, Natal, 2015.

TREICHEL, M. et al. Anuário Brasileiro da Fruticultura 2016. Santa Cruz do Sul: Gazeta Santa Cruz, 2016.

Recebido em: 27 setembro de 2016 Aceito em: 01 de março de 2017 